\title{
Harnessing RNA sequencing for global, unbiased evaluation of two new adjuvants for dendritic-cell immunotherapy
}

\author{
Till S.M. Mathan ${ }^{1}$, Johannes Textor $^{1}$, Annette E. Sköld ${ }^{1,2}$, Inge Reinieren-Beeren ${ }^{1}$, \\ Tom van Oorschot ${ }^{1}$, Mareke Brüning ${ }^{3}$, Carl G. Figdor ${ }^{1}$, Sonja I. Buschow ${ }^{1,4, *}$, Ghaith \\ Bakdash $^{1, *}$, I. Jolanda M. de Vries ${ }^{1,5}$ \\ ${ }^{1}$ Department of Tumor Immunology, Radboud Institute for Molecular Life Sciences, Radboud University Medical Centre, \\ Nijmegen, The Netherlands \\ ${ }^{2}$ Department of Oncology and Pathology, Karolinska University Hospital Solna, Karolinska Institute, Stockholm, Sweden \\ ${ }^{3}$ Miltenyi Biotec GmbH, Bergisch Gladbach, Germany \\ ${ }^{4}$ Department of Gastroenterology and Hepatology, Erasmus MC-University Medical Center, Rotterdam, The Netherlands \\ ${ }^{5}$ Department of Medical Oncology, Radboud University Medical Centre, Nijmegen, The Netherlands \\ *Authors contributed equally \\ Correspondence to: I. Jolanda M. de Vries, email: Jolanda.deVries@radboudumc.nl \\ Keywords: dendritic cells, immunotherapy, RNA sequencing, adjuvants, protamine-RNA, transcriptomics \\ Received: September 09, 2016 \\ Accepted: December 05, 2016 \\ Published: February 08, 2017
}

\section{ABSTRACT}

Effective stimulation of immune cells is crucial for the success of cancer immunotherapies. Current approaches to evaluate the efficiency of stimuli are mainly defined by known flow cytometry-based cell activation or cell maturation markers. This method however does not give a complete overview of the achieved activation state and may leave important side effects unnoticed. Here, we used an unbiased RNA sequencing (RNA-seq)-based approach to compare the capacity of four clinical-grade dendritic cell (DC) activation stimuli used to prepare DC-vaccines composed of various types of DC subsets; the already clinically applied GM-CSF and Frühsommer meningoencephalitis (FSME) prophylactic vaccine and the novel clinical grade adjuvants protamine-RNA complexes (PRNA) and CPG-P. We found that GM-CSF and pRNA had similar effects on their target cells, whereas pRNA and CpG-P induced stronger type I interferon (IFN) expression than FSME. In general, the pathways most affected by all stimuli were related to immune activity and cell migration. GMCSF stimulation, however, also induced a significant increase of genes related to nonsense-mediated decay, indicating a possible deleterious effect of this stimulus. Taken together, the two novel stimuli appear to be promising alternatives. Our study demonstrates how RNA-seq based investigation of changes in a large number of genes and gene groups can be exploited for fast and unbiased, global evaluation of clinicalgrade stimuli, as opposed to the general limited evaluation of a pre-specified set of genes, by which one might miss important biological effects that are detrimental for vaccine efficacy.

\section{INTRODUCTION}

Antigen presenting cells, such as Dendritic cells (DCs), play a central role in many immunotherapies because of their ability to induce immune responses or to promote immune tolerance by interacting with $\mathrm{CD}_{4}^{+}$ and $\mathrm{CD} 8^{+} \mathrm{T}$ cells. For $\mathrm{T}$ cell activation to occur, DCs need to mature and migrate to the lymph nodes. DC immunotherapies aim to strengthen antitumoral immune responses by boosting $\mathrm{T}$ cell activation $[1,2]$. In such therapies, DCs are isolated, activated and loaded with tumor antigen and then given back to the patient. Vaccine DCs are anticipated to promote antitumor responses by presenting tumor antigen in the context of costimulatory molecules and immune-stimulatory cytokines [3-7]. Upon activation, DCs upregulate costimulatory markers 
like CD40 and CD80, but also co-inhibitory markers, such as PD-L1, PD-L2, IL-10 and TGF- $\beta$, which are essential for the termination of an immune response. Expression of the right maturation markers and secretion of the right cytokines is thus important for vaccine success and these therefore need to be taken into account when selecting the optimal adjuvant for the activation of vaccine $\mathrm{DCs}$.

We perform immunotherapies with naturally occurring DCs, namely $\mathrm{CD} 1 \mathrm{c}^{+}$myeloid dendritic cells (mDCs) and plasmacytoid dendritic cells (pDC) $[8,9]$. These two subsets possess complementary phenotypes: they secrete different cytokines, express different pattern recognition receptors (PPR), and even take different, incompletely understood, migratory routes [10-14]. Mature plasmacytoid DCs respond to viruses and are known to produce large amounts of type I IFNs upon activation and may also induce $\mathrm{T}$ cell responses [1520]. Their counterparts, the $\mathrm{CD} 1 \mathrm{c}^{+} \mathrm{mDCs}$, respond to various microbial and fungal stimuli and induce Th1 responses via the production of IL-12 upon maturation [11,21-23]. Successful activation of naïve $\mathrm{CD} 8^{+} \mathrm{T}$ cells to cytotoxic $\mathrm{CD}^{+}$lymphocytes (CTLs) is of high interest for immunotherapies, since CTLs specifically target the cancerous cells $[24,25]$. In several clinical studies, the presence of CTLs was associated with a higher survival or increased clinical response [26-28]. Taken together, because both DC subsets are able to provoke a Th1 response, combining them may increase the efficacy of the antitumor immune response. Our clinical trials with either pDCs, stimulated by FSME (an inactivated tick borne encephalitis virus that most likely binds to TLR7/8), or with $\mathrm{CD} 1 \mathrm{c}^{+} \mathrm{mDC}$ s using GM-CSF (a growth factor that promotes myeloid cell maturation), highlighted the antitumor potential and positive clinical outcome in melanoma patients $[8,9]$.

The only available good manufacturing practice (GMP) grade TLR7/8 ligand is pRNA, a complex of protamine and mRNA, which most likely triggers TLR7/8, similar to FSME [29]. Sköld et al. have recently shown that pRNA activates $\mathrm{CD} 1 \mathrm{c}^{+} \mathrm{mDCs}$ and $\mathrm{pDCs}$ and induces them to release IL-12 and IFN- $\alpha$, respectively, making it a promising candidate to use for vaccines containing both subsets [30]. These findings prompted us to further inspect the effect of pRNA on DC activation. Furthermore, we investigated another novel clinical grade pDC activation stimulus, CpG-P. CpG ODNs are short single-stranded DNA molecules containing unmethylated $\mathrm{CpG}$ dinucleotides and can be divided in different classes depending on their effects. CpG-C and CpG-P combine both effects of CpG-A and CpG-B, namely strong IFN- $\alpha$ release and strong maturation marker upregulation [31, 32].

In our study we obtained and analyzed RNA sequencing data of the two DC subsets using these new clinical grade adjuvants conditions to obtain a comprehensive and unbiased overview of the effect of each stimulus on the phenotype of the activated DCs. Focusing only on specific maturation markers and cytokines may lead to a loss of relevant findings. Recently, the relevance of implementing systems biology in vaccine research has been demonstrated by studying the effect of human adjuvants in animal models with transcriptome profiling [33-35]. Because of its unbiased nature, system vaccinology may help to understand which immunological processes are detrimental for vaccine success [36-38]. In the present study, we applied principal coordinate analysis $(\mathrm{PCoA})$ and gene ontology (GO) analysis to evaluate the effect of each adjuvant on the whole cell rather than selected maturation markers and cytokines only. Using these approaches, we compared the previously used DC activation stimuli, GM-CSF for CD1 $\mathrm{c}^{+} \mathrm{mDCs}$ and FSME for pDCs, with the novel stimuli, pRNA and CpG-P, and validated several of our findings with functional assays. Our data indicate that both pRNA and CpG-P are suitable clinical grade adjuvants for the activation of either both DC subsets together or pDCs alone.

\section{RESULTS}

\section{RNA-seq gene expression levels are comparable with protein levels}

To evaluate the transcriptome of the two DC subsets upon activation with different stimuli, we performed whole-cell RNA sequencing of magnetic bead isolated $\mathrm{CD} 1 \mathrm{c}^{+} \mathrm{mDCs}$ and $\mathrm{pDCs}$ of the same donors. To this aim, DC transcriptomes were analyzed directly after isolation or following 6 hours of stimulation with either IL-3 alone, FSME and IL-3 or pRNA and IL-3 (pDCs) or GM-CSF, pRNA $\left(\mathrm{CD} 1 \mathrm{c}^{+} \mathrm{mDCs}\right)$. First, we were interested in whether this approach would give comparable results as targeted flow cytometry evaluation of established DC maturation markers. Here we chose the markers CD80, PDL-1, and CD40 (Figure $1 \mathrm{~A}-1 \mathrm{C})$ as representatives for the maturation state of these DC subsets. CD80 is a co-stimulatory maturation marker also used in our clinical set up to determine the maturation state of the DCs $[8,39]$. PD-L1 as a coinhibitory and CD40 as an additional co-stimulatory marker were considered suitable candidates to complete the set, because both maturation markers are known to be expressed on both cell subsets [40]. Comparing the different conditions of pDCs with each other, we found that the overall pattern of RNA and protein expression was similar. The survival factor IL-3 showed no or very little effect on the expression of the maturation markers, except on CD40 (Figure 1C). FSME and pRNA, showed a similar upregulation of maturation markers CD80, PDL-1 and CD40 on pDCs. In CD1 ${ }^{+} \mathrm{mDCs}$, GMCSF or pRNA caused an upregulation of all maturation 
A
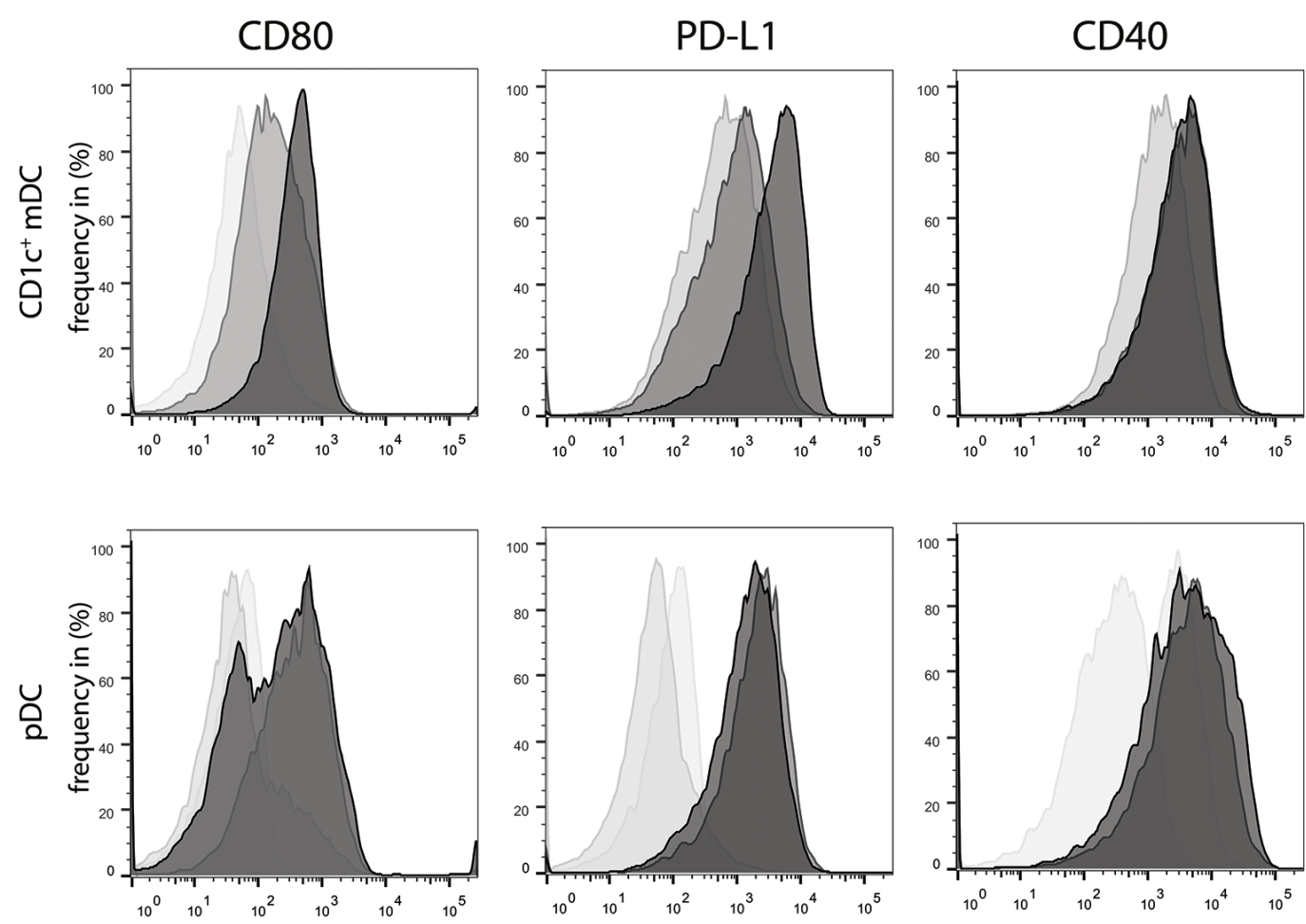

B

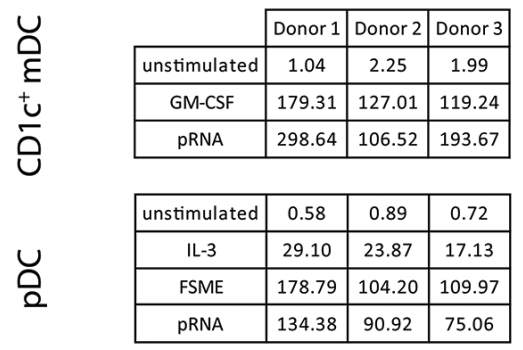

\begin{tabular}{|c|c|c|c|}
\cline { 2 - 4 } \multicolumn{1}{c|}{} & Donor 1 & Donor 2 & Donor 3 \\
\hline unstimulated & 1.08 & 0.89 & 1.35 \\
\hline GM-CSF & 271.92 & 161.19 & 140.01 \\
\hline PRNA & 561.97 & 182.61 & 374.70 \\
\hline
\end{tabular}

\begin{tabular}{|c|c|c|c|}
\cline { 2 - 4 } \multicolumn{1}{c|}{} & Donor 1 & Donor 2 & Donor 3 \\
\hline unstimulated & 2.32 & 15.58 & 10.65 \\
\hline GM-CSF & 153.12 & 367.43 & 402.67 \\
\hline pRNA & 90.74 & 195.70 & 256.34 \\
\hline
\end{tabular}

C

CD80

\begin{tabular}{|c|c|c|c|}
\hline unstimulated & 1.04 & 0.89 & 0.93 \\
\hline IL-3 & 8.26 & 3.28 & 4.63 \\
\hline FSME & 460.47 & 279.39 & 193.60 \\
\hline pRNA & 481.07 & 244.54 & 206.01 \\
\hline
\end{tabular}

\begin{tabular}{|c|c|c|c|}
\hline unstimulated & 1.00 & 4.91 & 5.09 \\
\hline IL-3 & 33.12 & 43.94 & 38.09 \\
\hline FSME & 197.25 & 153.00 & 109.07 \\
\hline PRNA & 287.30 & 874.03 & 458.57 \\
\hline
\end{tabular}

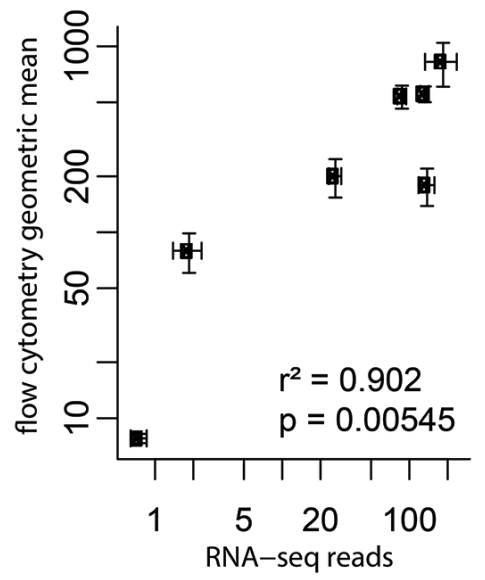

PD-L1

CD40
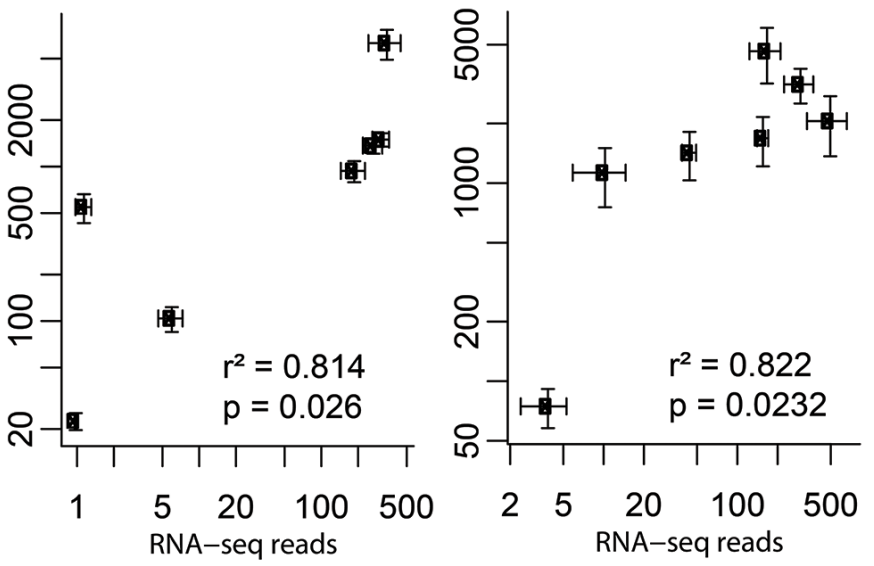

Figure 1: RNA-seq results represent protein levels. A. Flow cytometry histograms for three maturation markers (CD80, PD-L1 and $\mathrm{CD} 40$ ) on $\mathrm{pDCs}$ and $\mathrm{CD} 1 \mathrm{c}^{+} \mathrm{mDCs}$. For CD1c: Light grey represents unstimulated samples, dark grey represents GM-CSF samples, and black represents pRNA samples. For pDC: bright transparent grey represents the unstimulated samples, light grey represents the IL-3 samples, grey represents FSME and black represents pRNA samples. B. Gene expression levels of the 3 donors of the RNA-seq. C. Correlation plot of the RNA-seq counts/1 million reads set out against the geometric mean fluorescence intensity as measured by flow cytometry (protein level). Throughout this paper, error bars represent standard error of the mean. 
markers, at both RNA and protein levels. However, there were some differences in the strength of the two stimuli: pRNA appeared to have a stronger affect on CD80 and PD-L1 RNA and protein expression. GM-CSF induced stronger CD40 RNA expression but this was not found at the protein level. In order to further delineate the relation between RNA-seq reads and protein expression levels, we performed a Spearman nonparametric correlation analysis with the RNA sequencing samples of the 3 donors and compared them to protein expression values of 6 different donors. All three maturation markers showed strong correlations between RNA and protein levels (CD80: $\mathrm{r}^{2}=0.902, \mathrm{p}=0.00545$; PD-L1: $\mathrm{r}^{2}=0.814$, $\mathrm{p}=0.026$; CD40: $\mathrm{r}^{2}=0.822, \mathrm{p}=0.0232$ ). Altogether, RNA seq data well reflected flow cytometry data indicating the biological relevance of changes in RNA expression values. Furthermore, this first analysis suggests that pRNA is equally or even more potent than currently used clinical grade stimuli in the activation of $\mathrm{CD} 1 \mathrm{c}^{+} \mathrm{mDCs}$ and pDCs.

\section{Clinical grade stimuli have similar overall effects on both cell types}

Having confirmed the validity of RNA-seq for evaluating DC maturation status, we were interested in how specific stimuli affect the entire DC transcriptome, rather than a small pre-defined set of maturation markers. Therefore, we applied principal coordinates analysis (PCoA) on the gene expression data of all DC types and conditions tested, separately per donor. The first two principal coordinates are shown in Figure 2A. The first coordinate (X axis) aligned roughly with the cell type ( $\mathrm{pDC}$ versus $\mathrm{CD}^{+} \mathrm{c}^{+} \mathrm{mDC}$ ), whereas the second coordinate reflected maturation status. The overall picture was similar between the three donors, indicating good reproducibility of the RNA sequencing.

A
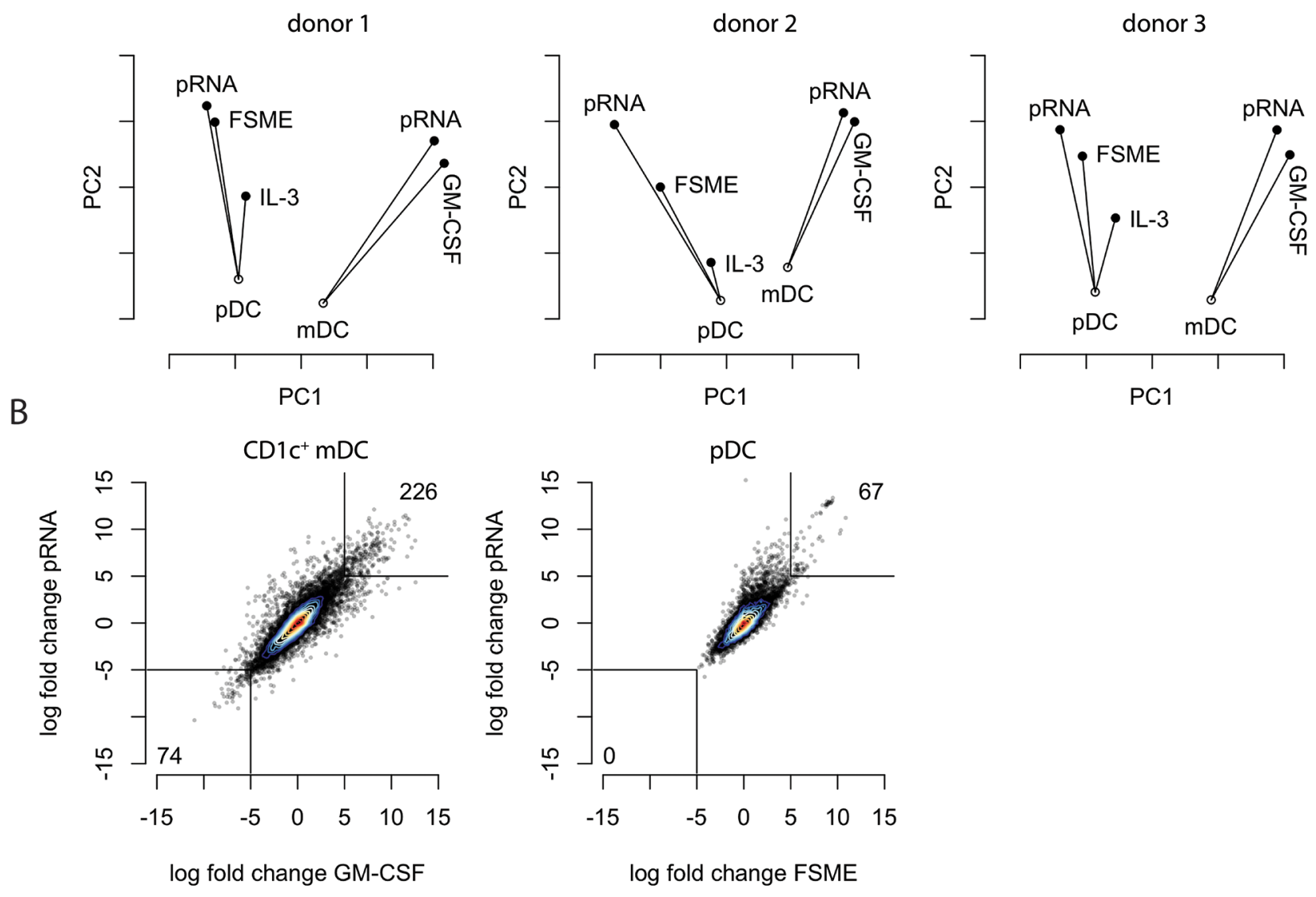

Figure 2: RNA-seq-based global assessment of DC responses to clinical stimuli. A. Principal coordinates analysis (PCoA) of $\mathrm{pDCs}$ and $\mathrm{CD} 1 \mathrm{c}^{+} \mathrm{mDCs}$ was performed for each of the stimuli to compare their similarities in gene expression. Each point represents the transcriptome of the respective condition and the analysis was based on the first and second coordinate. On the $\mathrm{x}$-axis the principle coordinate one (PCO1) is displayed, on the y-axis the principle coordinate two (PCO2). B. Correlation plots depicting the gene expression changes upon each stimulus for each subset. Each point represents a gene. 
In both DC subsets the new stimulus, pRNA, showed a similar effect as the previously used stimuli FSME and GM-CSF. While the differences in effects between GM-CSF and pRNA, as measured by the first two principal coordinates, were very small for $\mathrm{CD} 1 \mathrm{c}^{+} \mathrm{mDCs}$, the differences between stimuli were more pronounced on pDCs. Using the unstimulated pDCs as the reference point, the FSME sample and pRNA did align along the same axis, but pRNA was located further away from the unstimulated cells. This suggests that both stimuli affect the RNA expression of roughly the same genes, but that pRNA has an overall stronger effect on these genes. Furthermore, the data indicated that upon stimulation, the differences between the two DC phenotypes increased.

To directly compare the established and the novel stimuli for each of the two cell types, we correlated the fold-changes of each gene relative to unstimulated cells (for $\mathrm{CD} 1 \mathrm{c}^{+} \mathrm{mDCS}$ ) or to IL3-treated cells (for $\mathrm{pDCs}$ ) of existing and novel activation stimuli (Figure 2B). Both plots confirmed the overall similar effect of the existing and novel stimuli on the transcriptome we already observed by PCoA. In line with PCoA, a slight skewing of the pDC correlation plot towards pRNA indicated that indeed pRNA had a stronger effect than FSME on mostly the same set of genes. Interestingly, for pDCs more genes were highly upregulated ( $>10$ fold) than highly downregulated by both stimuli, whereas for $\mathrm{CD}^{+} \mathrm{c}^{+} \mathrm{mDCs}$ this difference was less pronounced (Figure 2B).

To find out which biologically coherent gene groups were most affected by the different stimuli, a gene ontology (GO) term analysis was performed (Table 1) on all significantly $(\mathrm{p}<0.05$ after multiple testing correction with the Benjamini-Hochberger method) up- and downregulated genes of each subset. This qualitative method also provided insight in affected pathways and gene groups not directly connected to DC maturation. Overall, all stimuli most strongly affected immune response-related genes. However, GM-CSF treatment of CD1 $\mathrm{c}^{+}$mDCs also clearly affected a number of gene clusters that are not directly linked to immune response. Of note, one of these clusters was "nonsense-mediated decay" [41], pointing to a possible deleterious effect.

Together, the whole-transcriptome analysis indicated that pRNA had similar effects on both cell types as the existing cell type-specific stimuli. However, pRNA appeared to have an overall stronger maturation effect on pDCs and a similar effect on $\mathrm{CD} \mathrm{c}^{+} \mathrm{mDC}$ compared to the previously used stimuli. Importantly, unlike GM-CSF, pRNA did not have any obvious negative effects on $\mathrm{CD} 1 \mathrm{c}^{+}$ mDCs.

\section{Discrepancies between pRNA stimulated pDCs and $\mathrm{CD} 1 \mathrm{c}^{+} \mathrm{mDCs}$}

Besides the overall similarities among used stimuli, we also observed differences between the effects of the existing and novel stimuli on each cell subset. A limitation of the GO term analysis is that it does not take into account the magnitude of the expression changes and therefore no conclusions on these can be drawn. Therefore, as a complementary approach, we generated Volcano plots of the overall fold-changes and p-values for each gene based on the combined data from all 3 donors. These plots show that pRNA in CD1c $\mathrm{c}^{+}$mDCs caused a strong upregulation of cytokines and migration-related genes (Figure 3 ). In $\mathrm{CD} \mathrm{c}^{+} \mathrm{mDCs}$ stimulated with GMCSF, several chemokines (CXCL5, CCL1 CSF1, CCL24 and CCL22) were upregulated 12-13 fold. Upon activation with pRNA, chemokines were once again found among the most upregulated genes. Except for CXCL5 and CCL17, these genes were upregulated to a very similar extent as upon GM-CSF stimulation. Comparing the chemokines with each other, the fold changes were almost on the same level between the two stimuli (Figure 3A and 3B).

In pDCs, multiple genes related to type I and III interferons (IFN- $\alpha$ and IFN- $\lambda$ ) were found among the most strongly and significantly upregulated genes. While pRNA lead to a significant increase of the transcription of various subtypes of IFN- $\alpha$ and IFN- $\lambda$ (IL28/ IL29), FSME upregulated the chemokines CXCL9, CXCL10 and CXCL11 when compared to unstimulated pDCs. As already indicated by PCoA and correlation plots (Figure 2), the overall extent of gene expression increase upon FSME was less than upon pRNA stimulation. For instance, whereas FSME caused a $>10$-fold increase for only 3 genes, pRNA did so for 26 genes. Several IFN- $\alpha$ subtypes showed 13-fold increases when stimulated with pRNA, compared to 9- to 10-fold for FSME (Figure 3C and 3D). As expected the difference between DC subtypes was most prominent for type I IFNs, pRNA induced no IFN- $\alpha$ production in $\mathrm{CD} \mathrm{c}^{+} \mathrm{mDCs}$ in contrast to high levels in pDCs. In pDCs, all 13 type I IFN genes were upregulated upon pRNA stimulation in all 3 donors (Figure 4A). We confirmed this observation at the protein level in 7 donors and detected a significantly higher (10fold, $\mathrm{p}<0.001)$ release of IFN- $\alpha$ upon $\mathrm{pRNA}$ compared to FSME stimulation (Figure 4B).

To assess the effect of pRNA on CD $1 \mathrm{c}^{+} \mathrm{mDC}$, we assessed additional immunostimulatory cytokines that are known to be relevant for this subset. Based on the RNAseq data, the gene expression of the immunostimulatory cytokines IL-12p40, IL-23 and IL-6 increased significantly upon pRNA stimulation (Figure 5A). TNF- $\alpha$, another immunostimulatory cytokine, was increased on both $\mathrm{pDCs}$ and (less strongly) on $\mathrm{CD}^{+} \mathrm{c}^{+} \mathrm{mDCs}$. Additionally, the transcription of the immunoinhibitory cytokine IL10 increased by pRNA stimulation compared to the unstimulated and GM-CSF-stimulated samples. We chose IL12p70 and TNF- $\alpha$ as representing cytokines to confirm the RNA-seq results on the protein level (Figure 5B). IL12 p70 release showed the same pattern as the RNA-seq counts, whereas for TNF- $\alpha$ release the results differed 
Table 1: Clinical stimuli affect similar gene clusters in pDCs but less so in CD1 $\mathrm{c}^{+} \mathrm{mDCs}$

\begin{tabular}{|c|c|c|c|c|}
\hline term & ontology & $\mathbf{N}$ genes & N up/down & - $\log \_10$ p-value \\
\hline \multicolumn{5}{|l|}{ CD1c $^{+}$mDC GM-CSF } \\
\hline cytosolic ribosome & $\mathrm{CC}$ & 103 & 62 & 25.4 \\
\hline extracellular region part & $\mathrm{CC}$ & 3752 & 755 & 22.5 \\
\hline SRP-dependent cotranslational protein targeting to membrane & $\mathrm{BP}$ & 108 & 60 & 22.1 \\
\hline cotranslational protein targeting to membrane & $\mathrm{BP}$ & 110 & 60 & 21.5 \\
\hline $\begin{array}{l}\text { nuclear-transcribed mRNA catabolic process, nonsense-mediated } \\
\text { decay }\end{array}$ & $\mathrm{BP}$ & 120 & 63 & 21.4 \\
\hline immune system process & $\mathrm{BP}$ & 2576 & 547 & 20.6 \\
\hline protein targeting to ER & BP & 114 & 60 & 20.5 \\
\hline extracellular region & $\mathrm{CC}$ & 4482 & 862 & 20.0 \\
\hline establishment of protein localization to endoplasmic reticulum & BP & 118 & 60 & 19.5 \\
\hline regulation of multicellular organismal process & $\mathrm{BP}$ & 2403 & 507 & 18.4 \\
\hline \multicolumn{5}{|l|}{ CD1c $c^{+}$mDC pRNA } \\
\hline immune system process & BP & 2576 & 578 & 21.3 \\
\hline regulation of cell migration & $\mathrm{BP}$ & 593 & 177 & 17.8 \\
\hline cell surface receptor signaling pathway & $\mathrm{BP}$ & 2677 & 580 & 17.8 \\
\hline regulation of cell motility & BP & 628 & 184 & 17.6 \\
\hline immune response & $\mathrm{BP}$ & 1626 & 383 & 17.2 \\
\hline regulation of cellular component movement & $\mathrm{BP}$ & 704 & 199 & 17.1 \\
\hline inflammatory response & $\mathrm{BP}$ & 616 & 180 & 17.1 \\
\hline extracellular region part & $\mathrm{CC}$ & 3752 & 764 & 16.6 \\
\hline response to organic substance & $\mathrm{BP}$ & 2828 & 601 & 16.5 \\
\hline regulation of locomotion & BP & 690 & 194 & 16.4 \\
\hline \multicolumn{5}{|l|}{ pDC FSME } \\
\hline immune response & $\mathrm{BP}$ & 1626 & 127 & 26.9 \\
\hline immune system process & $\mathrm{BP}$ & 2576 & 165 & 25.9 \\
\hline response to type I interferon & $\mathrm{BP}$ & 85 & 30 & 24.7 \\
\hline response to virus & $\mathrm{BP}$ & 403 & 57 & 23.7 \\
\hline type I interferon signaling pathway & BP & 84 & 29 & 23.6 \\
\hline cellular response to type I interferon & $\mathrm{BP}$ & 84 & 29 & 23.6 \\
\hline defense response to virus & BP & 325 & 51 & 23.3 \\
\hline response to biotic stimulus & BP & 904 & 85 & 22.7 \\
\hline response to external biotic stimulus & BP & 869 & 82 & 22.0 \\
\hline response to other organism & $\mathrm{BP}$ & 869 & 82 & 22.0 \\
\hline \multicolumn{5}{|l|}{ pDC pRNA } \\
\hline response to virus & $\mathrm{BP}$ & 403 & 73 & 24.4 \\
\hline \multirow[t]{2}{*}{ immune response } & $\mathrm{BP}$ & 1626 & 166 & 24.3 \\
\hline & & & & (Continued) \\
\hline
\end{tabular}




\begin{tabular}{lcccc}
\hline term & ontology & N genes & N up/down & - $\log _{\text {_10 }}$ p-value \\
\hline immune system process & BP & 2576 & 222 & 23.1 \\
cytokine activity & MF & 218 & 51 & 22.3 \\
response to type I interferon & BP & 85 & 33 & 22.2 \\
defense response to virus & BP & 325 & 62 & 22.0 \\
response to external biotic stimulus & BP & 869 & 107 & 21.4 \\
response to other organism & BP & 869 & 107 & 21.4 \\
type I interferon signaling pathway & BP & 84 & 32 & 21.2 \\
cellular response to type I interferon & BP & 84 & 32 & 21.2 \\
\hline
\end{tabular}

Changes in gene expression clusters were detected by performing a GO term analysis. Of each stimulus the top 10 most differential expressed gene clusters were selected. The description for each gene cluster is mentioned in the columns. The ontology defines the sub-ontology: molecular function (MF), cellular component (CC) and biological process (BP). $N$ genes stands for the total amount of genes for this gene cluster and $N$ up/down for the number of genes that changed their expression values upon the stimulus. The table is sorted on the $-\log _{10} \mathrm{p}$-value, which can be found in the column on the very right.

slightly from the RNA-seq data: On protein level, pRNA was the most effective stimulus for TNF- $\alpha$ production on both cell types, whereas the RNA-seq counts suggested GM-CSF as a slightly more potent TNF- $\alpha$ stimulus.

Taken together, our results suggest pRNA to be a potent activation stimulus for $\mathrm{pDCs}$ as well as $\mathrm{CD} 1 \mathrm{c}^{+}$ $\mathrm{mDCs}$, reflected by a strong upregulation of type I IFN and chemokines.

\section{CpG-P as a clinical grade stimulus for pDCs}

Finally, we investigated $\mathrm{CpG}-\mathrm{P}$, a novel clinical grade TLR9 agonist, as a pDC-specific activator. These synthetic oligonucleotides mimic the effect of bacterial DNA and therefore may support Th1 responses. We used RNA-seq on pDCs from two donors to evaluate the effect of $\mathrm{CpG}-\mathrm{P}$ on pDCs and validated our findings with additional functional assays on protein level. For that purpose, we incorporated the CpG-P stimulated pDC samples into the PCoA analysis and evaluated their positions. The CpG-P samples appeared to be similar to pRNA in Donor 2 and close to both pRNA and FSME in Donor 3 regarding overall gene expression levels (Figure 6A). These results suggested that CpG-P is a strong activation stimulus for pDCs. To get a more detailed view of the changes in gene expression of DCspecific genes, we focused on the DC maturation markers shown in Figure 1. CpG-P induced a stronger upregulation of transcripts and proteins of all 3 maturation markers than FSME and pRNA (Figure 6B \& 6C). In addition to the maturation markers, the release of type I IFN was strongly upregulated by CpG-P (Supplementary Figure 1). Altogether, our RNA-seq method suggests CpG-P as a strong adjuvant for $\mathrm{pDCs}$.

\section{DISCUSSION}

In this study, we aimed to evaluate the efficiency of two novel clinical grade adjuvants in a comprehensive and unbiased manner. We therefore used RNA-seq to evaluate the effects of each stimulus on total gene expression in two DC subsets of interest for immunotherapy. This approach allowed us to directly and extensively compare the effects of different adjuvants on DC phenotypes, beyond conventional maturation markers [40]. With our approach we translated changes on the whole-transcriptome level to possibly functionally relevant effects. Firstly, the results revealed the effect of different stimuli in each donor and allowed us to draw conclusions based on these patterns. Secondly, the similarity of the results in all three donors indicated good reproducibility of this method. Importantly, we were able to confirm RNA-seq expression changes regarding maturation marker expression and cytokine release on protein level and therefore validate the expression differences we observed in the transcriptome. This allowed us to draw conclusions about the efficacy of the tested clinical grade stimuli.

The PCoA analysis generated a useful initial summary of the whole-transcriptome data into a simplified representation that nevertheless revealed striking relations between the individual datasets. Importantly, this approach allowed for an overall assessment of the "strength" of each stimulus. This analysis suggested that pRNA is potentially a stronger pDC stimulus than FSME, with qualitatively similar effects as indicated by the GO analysis (Table 1). We demonstrated in a previous study that pRNA-induced activation of $\mathrm{CD} 1 \mathrm{c}^{+} \mathrm{mDCs}$ leads to significantly higher IL12p70 release and a similar TNF- $\alpha$ production as R848 
and Poly IC, combined with lower immunosuppressive IL-10 production [30]. The robustness of these findings was corroborated by our functional assays on protein level. Additionally, based on PCoA, CpG-P was identified as a potentially strong stimulus for pDCs. Our functional assays confirmed this finding by showing that CpG-P not only upregulated the maturation markers significantly more than the other stimuli, it also led to a very high release of immunostimulatory cytokines such as IFN- $\alpha$. Since type I IFNs are known to play important roles in T
A

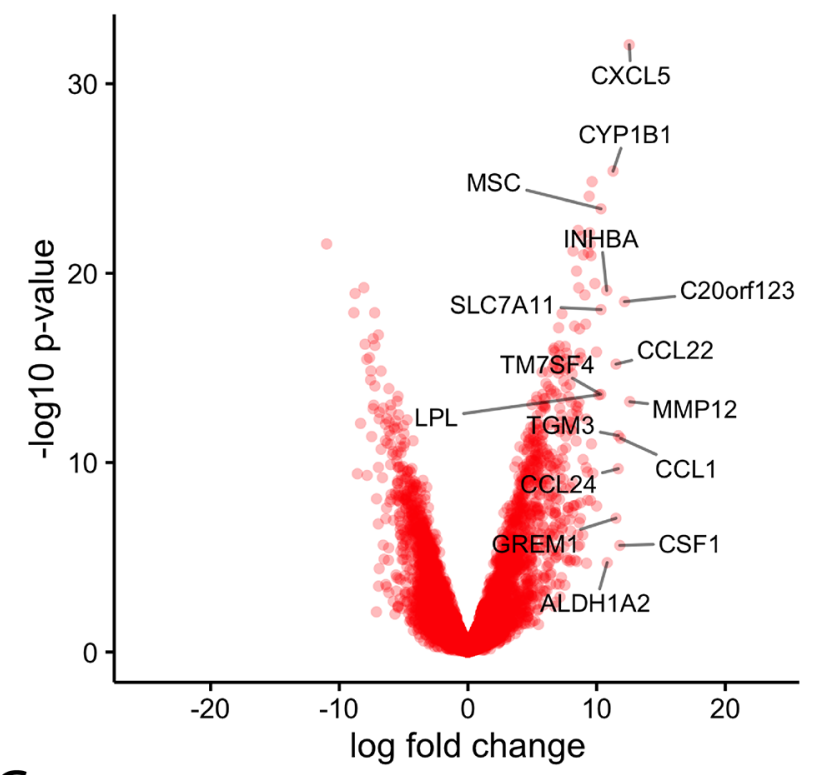

C

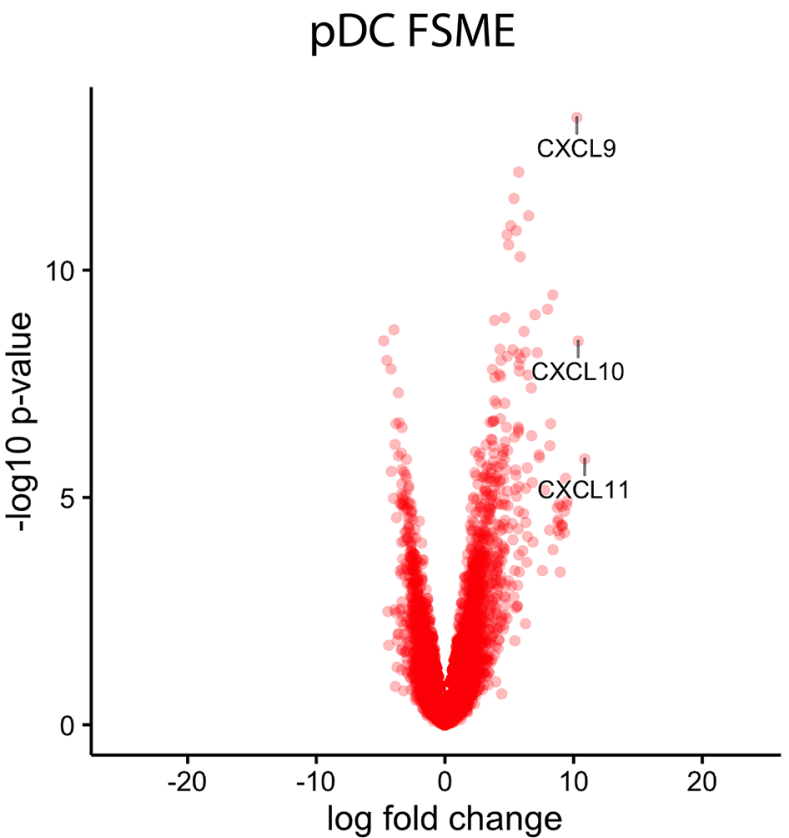

B

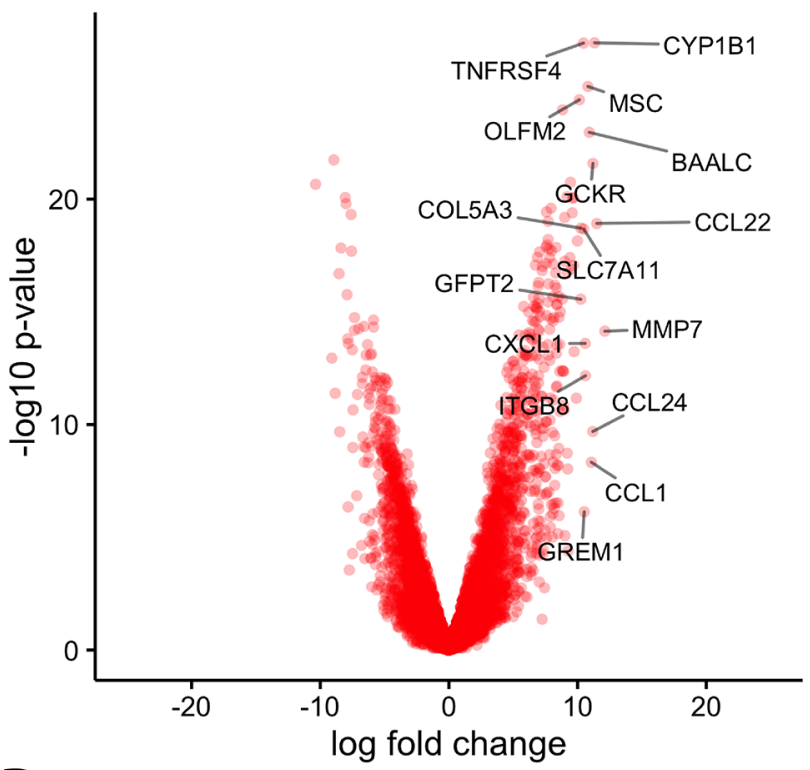

$\mathrm{D}$ pDC pRNA

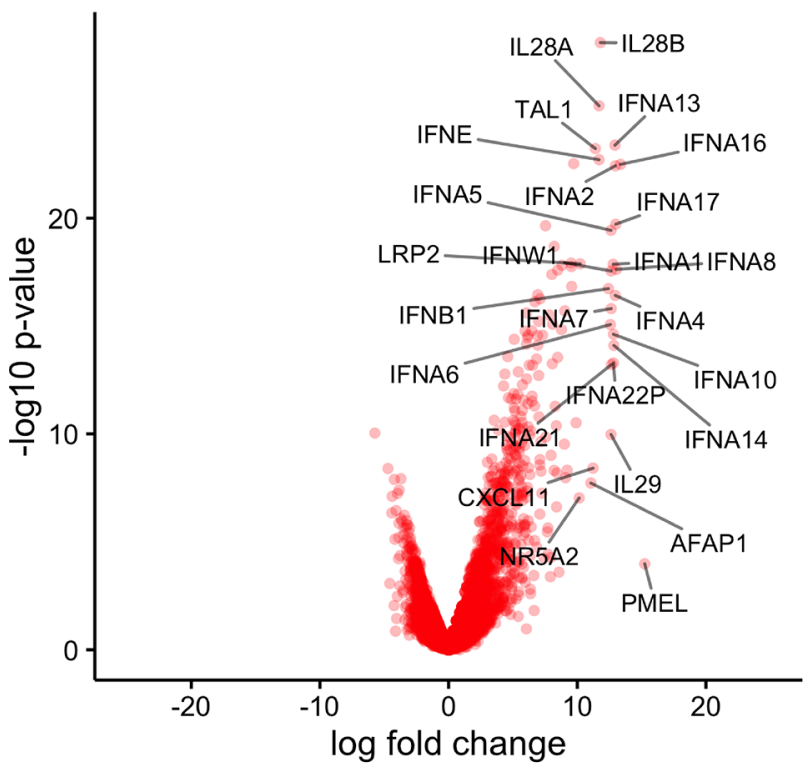

Figure 3: Stimuli effects on individual genes. A-D. Volcano plots representing the gene expression changes (x-axis: log fold) together with the statistical significance (y-axis: $-10 \log$ p-value). Each condition was compared to the respective unstimulated cell type. Genes with a log fold change of more than 10 were labeled with the gene name. A) GM-CSF stimulated CD1 $\mathrm{c}^{+}$mDC; B) pRNA stimulated CD1 $\mathrm{c}^{+}$mDCs; C) FSME stimulated pDCs; D) pRNA stimulated pDCs. 
cell activation, these findings suggest that $\mathrm{CpG}-\mathrm{P}$ could prove to be a potent $\mathrm{pDC}$ stimulus in immune therapies [42]. Interestingly, the transcriptome changes by CpG-P stimulation are very similar to the ones induced by pRNA, even though they stimulate different TLRs.

GM-CSF is widely used to differentiate in vitro monocytes into DCs and its high levels are connected to higher numbers of moDCs in vivo [43-47]. However, GM-CSF has been shown to inhibit pDC development via IRF8 [48]. GO-analysis of the effect of GM-CSF on $\mathrm{CD} \mathrm{c}^{+} \mathrm{mDC}$ indicated that upon GM-CSF stimulation, a significant number of genes belonging to the GO term "nuclear-transcribed mRNA catabolic process, nonsense-mediated decay (NMD)" were differentially expressed. This NMD pathway activates the destruction of mRNAs containing premature stop codons, which has negative side effects $[49,50]$. How this pathway affects the maturation process of $\mathrm{CD} \mathrm{c}^{+} \mathrm{mDCs}$ and

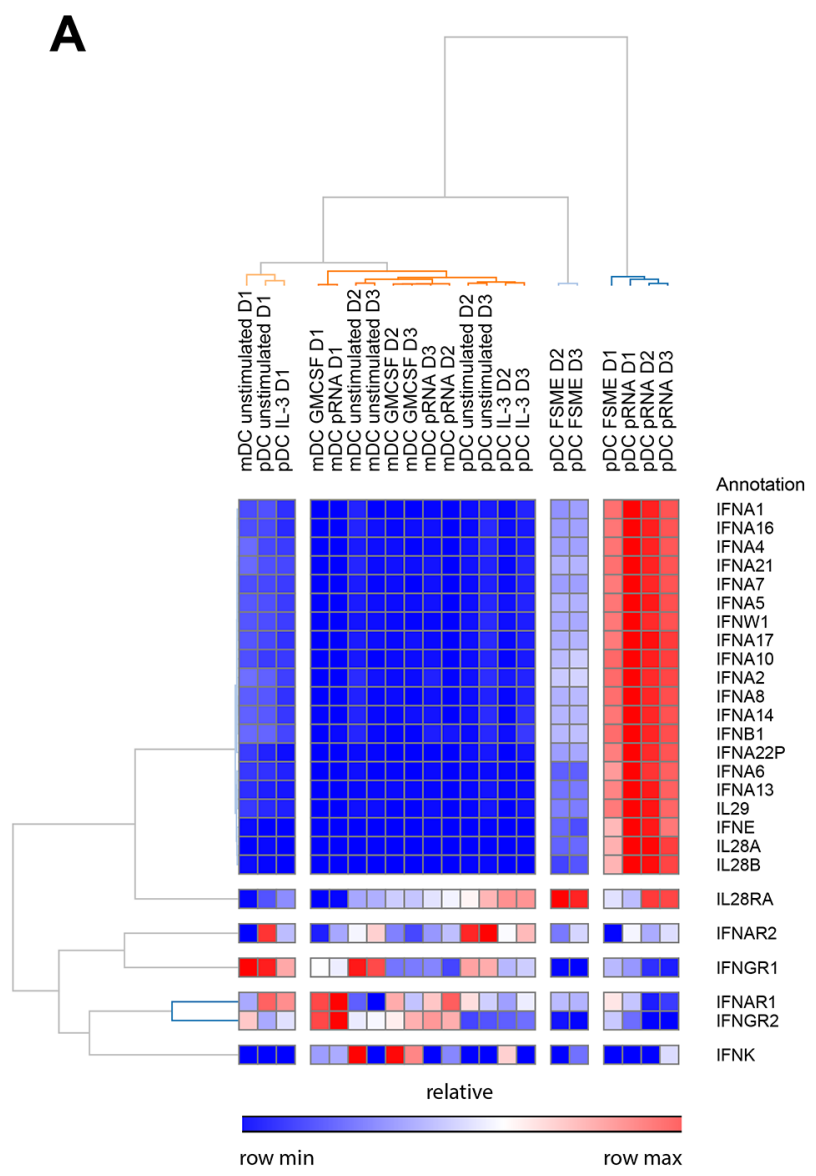

their functionality has not been reported yet, but it may be involved in inflammatory processes [51]. An unexpected side-effect like this would not have been found by using FACS analysis on an a priori defined, limited set of genes. This should be considered when GM-CSF is clinically applied, as inducing this gene cluster may have a negative impact on $\mathrm{CD}^{+} \mathrm{c}^{+} \mathrm{mDC}$ function.

Other studies have already applied RNA-seq to characterize DCs upon stimulation with antigen. For example, two recent studies have applied single cell RNA-seq in a non-clinical context to identify differences between DC subsets and the effect of pathogenic stimuli on these cells $[52,53]$. Furthermore, there is considerable interest to apply RNA-seq in the clinic for diagnostic purposes, with several applications already underway [54]. Complementing these efforts, our study highlights the usefulness of RNA-seq based approaches for the

\section{B}

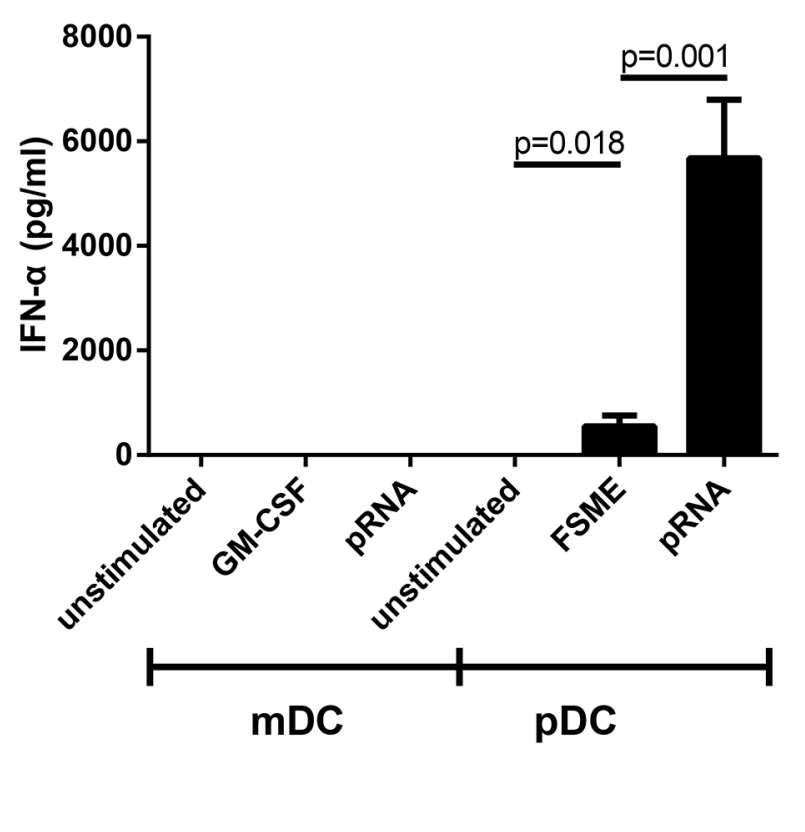

Figure 4: High type I/III interferon production of pDCs upon pRNA stimulation. A. Heat map of the type I/III interferon genes. Red colour represents high expression and blue low expression. B. Type I interferon levels on protein level measured in the supernatant of the stimulated cells after an overnight incubation $(n=7)$. 

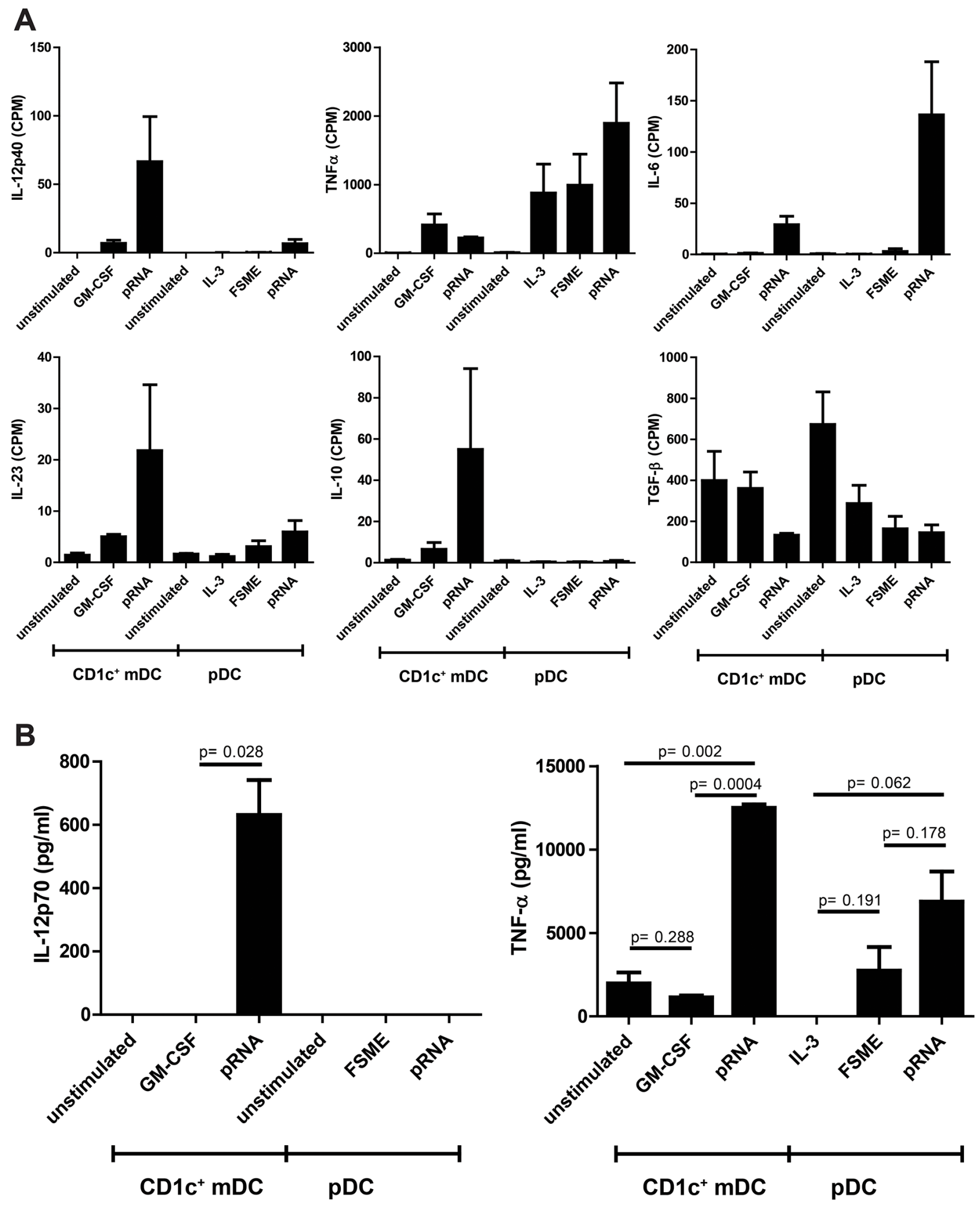

Figure 5: Pro-and anti-inflammatory cytokine release by $\mathbf{C D 1} \mathbf{c}^{+} \mathbf{m D C s}$ and pDCs. A. RNA expression values of several pro-inflammatory (IL-12p70, TNF- $\alpha$, IL-23 and IL6) and anti-inflammatory cytokines (IL-10 and TGF- $\beta$ ) of pDCs and CD1 $\mathrm{c}^{+} \mathrm{mDCs}$. B. IL-12p70 and TNF- $\alpha$ levels on protein level were measured in the supernatant of the stimulated cells after overnight incubation $(\mathrm{n}=3)$. 
design of clinical therapies, as it allows to determine the effects of certain stimuli on the target cells. In addition to RNA-seq, proteomics is another powerful unbiased approach that can be used to study the differences between DC subsets [55].

Taken together, a whole-transcriptome approach was used to analyze the effect of clinical grade stimuli on human DCs. This method provides a global, unbiased overview of how cells react to certain stimuli. In our case, we could confirm pRNA as a potent stimulus for both pDCs and $\mathrm{CD} \mathrm{c}^{+} \mathrm{mDCs}$ and introduce $\mathrm{CpG}-\mathrm{P}$ as a new clinical grade stimulus for $\mathrm{pDCs}$. In vitro, both new stimuli outperformed or had clear advantages over the existing stimuli.

A

donor 2

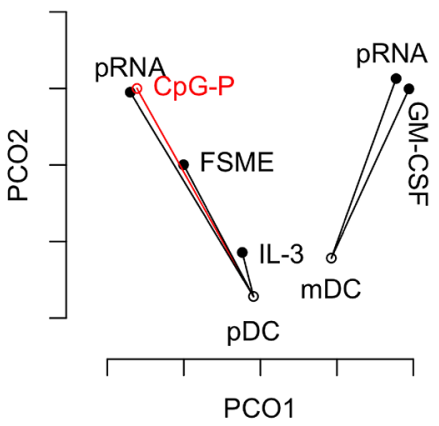

B

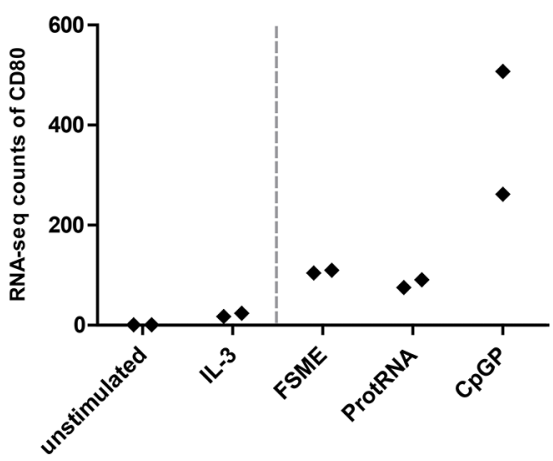

C

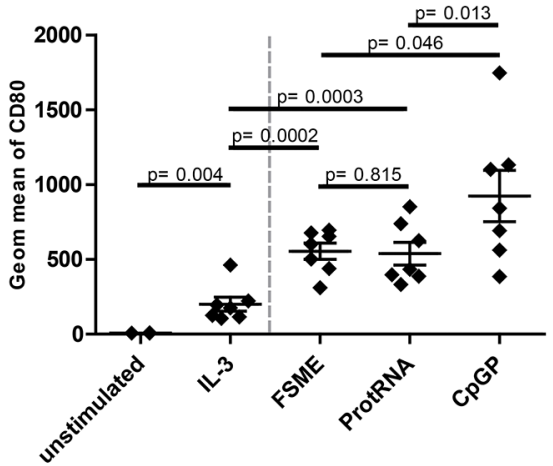

donor 3

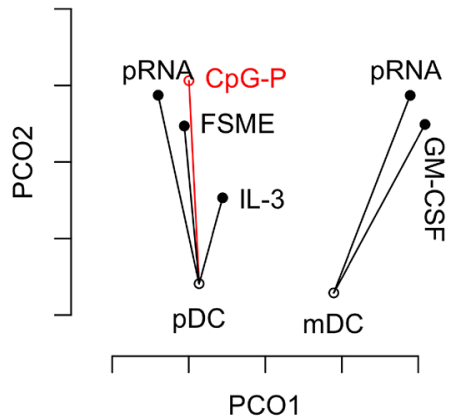

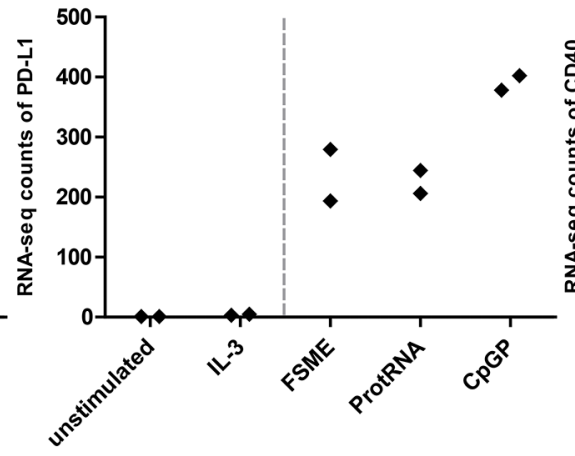
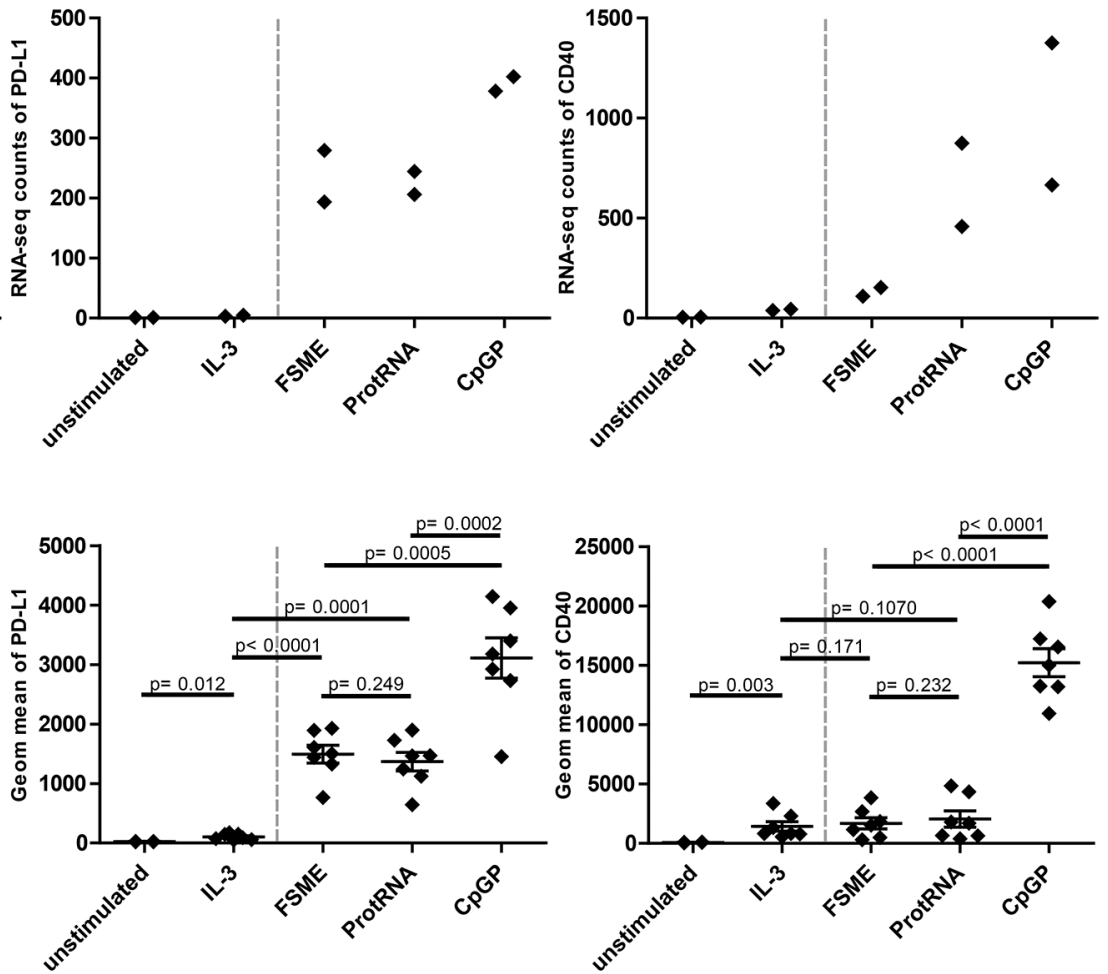

Figure 6: Assessment of CpG-P as a clinical-grade stimulus. A. PCoA of pDCs of donor 2 and 3 with CpG-P data included in the figure. Each point represents the transcriptome of the respective condition and the analysis was based on the first and second coordinate. B. Upregulation of the maturation markers on pDCs at RNA-seq level upon indicated stimuli $(\mathrm{n}=2)$. Upregulation of the maturation markers on $\mathrm{pDCs}$ at protein level upon the indicated stimuli $(\mathrm{n}=7)$. 


\section{MATERIALS AND METHODS}

\section{Cell isolation and culture}

For functional assays, DCs were isolated from buffy coats of healthy volunteers (Sanquin, Nijmegen, the Netherlands) after obtaining written informed consent per the Declaration of Helsinki and according to institutional guidelines. For RNA-seq measurements, cells were obtained from aphaeresis of 3 different donors. Peripheral blood mononuclear cells (PBMCs) were isolated by using Ficoll density centrifugation (Lymphoprep; Axis-Shield PoC AS, Oslo, Norway). $\mathrm{CD} 1 \mathrm{c}$ isolation kit of Miltenyi Biotec (BergischGladbach, Germany) was used to obtain $\mathrm{CD} 1 \mathrm{c}^{+} \mathrm{mDCs}$, by following manufacturer's instructions. Subsequently, monocytes were depleted by either plastic adhesion, or by the use of CD14 microbeads (Miltenyi Biotec). Next, pDCs were purified by positive selection using anti-BDCA-4-conjugated magnetic microbeads (Miltenyi Biotec). DCs were cultured in X-VIVO-15 medium (Lonza, Basel, Switzerland) supplemented with $2 \%$ human serum (Sanquin). DCs were stimulated

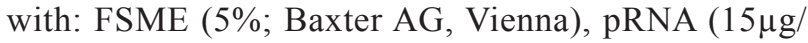
$\mathrm{ml})$, CpG-P $(5 \mu \mathrm{g} / \mathrm{ml}$; Miltenyi Biotech, Germany), GM-CSF ( $800 \mathrm{U} / \mathrm{ml}$; (Cellgenix, Freiburg, Germany). pRNA complexes were prepared fresh 5-10 minutes before adding to the cell culture. pDCs were cultured with $10 \mathrm{ng} / \mathrm{mL}$ IL-3 (Cellgenix, Freiburg, Germany) as a survival factor in addition to the stimuli.

\section{Protamine-RNA complexes}

pRNA complexes were made freshly before adding to the cells. Protamine (protaminehydrochloride MPH $5000 \mathrm{IE} / \mathrm{ml}$; Meda Pharma BV Amstelveen, the Netherlands) was diluted to $0.5 \mathrm{mg} / \mathrm{ml}$ in RNase free water and mixed with 2-kbp-long single-stranded mRNA (coding for gp100). It was extensively mixed and incubated for 5-10 minutes at room temperature, before added to the cells.

\section{FACS phenotyping}

The phenotype of $\mathrm{pDC}$ and $\mathrm{CD} 1 \mathrm{c}^{+} \mathrm{mDC}$ populations was determined by flow cytometry. DC purity was assessed by double staining $\mathrm{CD} 11 \mathrm{c}^{+} / \mathrm{CD} 1 \mathrm{c}^{+}$ for $\mathrm{CD} 1 \mathrm{c}^{+} \mathrm{mDCs}$ (above 95\%) and BDCA2/CD123 for pDCs (above 95\%; all Miltenyi Biotec) [56]. The following primary monoclonal antibodies (mAbs) were used to determine the maturation state of the DCs: anti-CD80-APC, anti-PD-L1-APC (all BD Bioscience Pharmingen, San Jose, CA); and anti-CD40-PE (Beckman Coulter, Marseille, France). Measurements were performed on FACSCalibur and FACSVerse flowcytometers (BD).

\section{Cytokine detection}

Supernatant was taken from each sample after overnight incubation and analyzed with standard sandwich ELISAs detecting IFN- $\alpha$ (Bender Medsystems, Vienna, Austria).

\section{RNA sequencing}

$\mathrm{CD} 1 \mathrm{c}^{+} \mathrm{mDCs}$ and $\mathrm{pDCs}$ were isolated as described above and total RNA was extracted using Trizol (Invitrogen, MA, USA), following the standard protocol. The quality control of the isolated RNA (concentration, RIN, 28S/18S and size) was performed with Agilent 2100 Bioanalyzer (Agilent Technologies, Santa Clara, USA). RNA sequencing and read alignment were performed by BGI TECH SOLUTIONS (Hong Kong). Reads were aligned to human genome version 19. RNA sequencing data is deposited at the Gene Expression Omnibus (GEO; accession number: GSE89442).

\section{Hierachical clustering}

Data was transformed to log values for performing hierarchical clustering analysis using the standard settings of the GENE-E software (Broad institute, Cambrige, MA; http://www.broadinstitute.org/cancer/software/GENE-E/ index.html).

\section{Statistical analysis}

Data was analyzed using the $\mathrm{R}$ platform for statistical computing. Specifically, the package "edgeR", version 3.12, was used for whole-transcriptome principal coordinates analysis (using the "plotMDS" command), differential expression analysis, and GO term analysis [57]. Differential expression was determined by fitting a generalized linear model using the "glmFit" command, and significance was determined using the likelihood ratio test provided by the "glmLRT" command [58]. The R scripts used to perform the data analysis are available as Supporting Information for this manuscript.

\section{Abbreviations}

pDC, plasmacytoid dendritic cells; $\mathrm{mDC}$, myeloid dendritic cells; RNA-seq, RNA sequencing; FSME, Frühsommer meningoencephalitis; GM- CSF, granulocytemacrophage colony-stimulating factor; pRNA, protamineRNA; CpG-P, CpG oligodeoxynucleotides; TLR, toll like receptor.

\section{CONFLICTS OF INTEREST}

M. Brüning is an employee of Miltenyi Biotec $\mathrm{GmbH}$. All authors declare that they have no competing financial interests. 


\section{FUNDING}

This work was supported by a Radboudume $\mathrm{PhD}$ grant and EU grant PROCROP (635122). IJMdV is recipient of NWO-Vici grant 918.14.655. CF is recipient of ERC Adv Grant (269019), an NWO Spinoza grant and KWO grant 2009-4402.

\section{RREFERENCES}

1. Bol KF, Schreibelt G, Gerritsen WR, de Vries IJ and Figdor CG. Dendritic Cell-Based Immunotherapy: State of the Art and Beyond. Clinical cancer research. 2016; 22:1897-1906.

2. Figdor CG, de Vries IJ, Lesterhuis WJ and Melief CJ. Dendritic cell immunotherapy: mapping the way. Nature medicine. 2004; 10:475-480.

3. Banchereau J, Briere F, Caux C, Davoust J, Lebecque S, Liu YJ, Pulendran B and Palucka K. Immunobiology of dendritic cells. Annual review of immunology. 2000; 18:767-811.

4. Heath WR and Carbone FR. Dendritic cell subsets in primary and secondary $\mathrm{T}$ cell responses at body surfaces. Nature immunology. 2009; 10:1237-1244.

5. Mcllroy D and Gregoire M. Optimizing dendritic cellbased anticancer immunotherapy: maturation state does have clinical impact. Cancer immunology, immunotherapy. 2003; 52:583-591.

6. de Vries IJ, Lesterhuis WJ, Scharenborg NM, Engelen LP, Ruiter DJ, Gerritsen MJ, Croockewit S, Britten CM, Torensma R, Adema GJ, Figdor CG and Punt CJ. Maturation of dendritic cells is a prerequisite for inducing immune responses in advanced melanoma patients. Clinical cancer research. 2003; 9:5091-5100.

7. De Vries IJ, Krooshoop DJ, Scharenborg NM, Lesterhuis WJ, Diepstra JH, Van Muijen GN, Strijk SP, Ruers TJ, Boerman OC, Oyen WJ, Adema GJ, Punt CJ and Figdor CG. Effective migration of antigen-pulsed dendritic cells to lymph nodes in melanoma patients is determined by their maturation state. Cancer research. 2003; 63:12-17.

8. Schreibelt G, Bol KF, Westdorp H, Wimmers F, Aarntzen EH, Duiveman-de Boer T, van de Rakt MW, Scharenborg NM, de Boer AJ, Pots JM, Olde Nordkamp MA, van Oorschot TG, Tel J, et al. Effective Clinical Responses in Metastatic Melanoma Patients after Vaccination with Primary Myeloid Dendritic Cells. Clinical cancer research. 2015.

9. Tel J, Aarntzen EH, Baba T, Schreibelt G, Schulte BM, Benitez-Ribas D, Boerman OC, Croockewit S, Oyen WJ, van Rossum M, Winkels G, Coulie PG, Punt CJ, Figdor $\mathrm{CG}$ and de Vries IJ. Natural human plasmacytoid dendritic cells induce antigen-specific T-cell responses in melanoma patients. Cancer research. 2013; 73:1063-1075.

10. Diebold SS, Kaisho T, Hemmi H, Akira S and Reis e Sousa C. Innate antiviral responses by means of TLR7-mediated recognition of single-stranded RNA. Science. 2004; 303:1529-1531.
11. Schreibelt G, Tel J, Sliepen KH, Benitez-Ribas D, Figdor CG, Adema GJ and de Vries IJ. Toll-like receptor expression and function in human dendritic cell subsets: implications for dendritic cell-based anti-cancer immunotherapy. Cancer immunology, immunotherapy. 2010; 59:1573-1582.

12. Kawai $\mathrm{T}$ and Akira S. Toll-like Receptors and Their Crosstalk with Other Innate Receptors in Infection and Immunity. Immunity. 2011; 34:637-650.

13. Kawai $\mathrm{T}$ and Akira $\mathrm{S}$. The role of pattern-recognition receptors in innate immunity: update on Toll-like receptors. Nature immunology. 2010; 11:373-384.

14. Geijtenbeek TBH and Gringhuis SI. Signalling through C-type lectin receptors: shaping immune responses. Nat Rev Immunol. 2009; 9:465-479.

15. Ito T, Liu YJ and Kadowaki N. Functional diversity and plasticity of human dendritic cell subsets. International journal of hematology. 2005; 81:188-196.

16. Kadowaki N, Antonenko S, Lau JY and Liu YJ. Natural interferon alpha/beta-producing cells link innate and adaptive immunity. The Journal of experimental medicine. 2000; 192:219-226.

17. Mathan TS, Figdor CG and Buschow SI. Human plasmacytoid dendritic cells: from molecules to intercellular communication network. Frontiers in immunology. 2013; 4:372.

18. Tel J, Lambeck AJ, Cruz LJ, Tacken PJ, de Vries IJ and Figdor CG. Human plasmacytoid dendritic cells phagocytose, process, and present exogenous particulate antigen. Journal of immunology. 2010; 184:4276-4283.

19. Salio M, Cella M, Vermi W, Facchetti F, Palmowski MJ, Smith CL, Shepherd D, Colonna M and Cerundolo V. Plasmacytoid dendritic cells prime IFN-gammasecreting melanoma-specific CD8 lymphocytes and are found in primary melanoma lesions. European journal of immunology. 2003; 33:1052-1062.

20. Fonteneau JF, Gilliet M, Larsson M, Dasilva I, Munz C, Liu YJ and Bhardwaj N. Activation of influenza virus-specific CD4+ and CD8+ T cells: a new role for plasmacytoid dendritic cells in adaptive immunity. Blood. 2003; 101:3520-3526.

21. Trinchieri G. Interleukin-12: a cytokine produced by antigen-presenting cells with immunoregulatory functions in the generation of T-helper cells type 1 and cytotoxic lymphocytes. Blood. 1994; 84:4008-4027.

22. Hemont C, Neel A, Heslan M, Braudeau C and Josien R. Human blood $\mathrm{mDC}$ subsets exhibit distinct TLR repertoire and responsiveness. Journal of leukocyte biology. 2013; 93:599-609.

23. Nizzoli G, Krietsch J, Weick A, Steinfelder S, Facciotti F, Gruarin P, Bianco A, Steckel B, Moro M, Crosti M, Romagnani C, Stolzel K, Torretta S, et al. Human $\mathrm{CD} 1 \mathrm{c}+$ dendritic cells secrete high levels of IL-12 and potently prime cytotoxic T-cell responses. Blood. 2013; 122:932-942. 
24. Anichini A, Fossati G and Parmiani G. Clonal analysis of cytotoxic T-lymphocyte response to autologous human metastatic melanoma. International journal of cancer. 1985; 35:683-689.

25. Molldrem JJ, Lee PP, Wang C, Felio K, Kantarjian HM, Champlin RE and Davis MM. Evidence that specific $\mathrm{T}$ lymphocytes may participate in the elimination of chronic myelogenous leukemia. Nature medicine. 2000; 6:1018-1023.

26. Haanen JB, Baars A, Gomez R, Weder P, Smits M, de Gruijl TD, von Blomberg BM, Bloemena E, Scheper RJ, van Ham SM, Pinedo HM and van den Eertwegh AJ. Melanoma-specific tumor-infiltrating lymphocytes but not circulating melanoma-specific T cells may predict survival in resected advanced-stage melanoma patients. Cancer immunology, immunotherapy. 2006; 55:451-458.

27. Galon J, Costes A, Sanchez-Cabo F, Kirilovsky A, Mlecnik B, Lagorce-Pages C, Tosolini M, Camus M, Berger A, Wind $\mathrm{P}$, Zinzindohoue F, Bruneval P, Cugnenc PH, Trajanoski Z, Fridman WH and Pages F. Type, density, and location of immune cells within human colorectal tumors predict clinical outcome. Science. 2006; 313:1960-1964.

28. Engell-Noerregaard L, Hansen TH, Andersen MH, Thor Straten P and Svane IM. Review of clinical studies on dendritic cell-based vaccination of patients with malignant melanoma: assessment of correlation between clinical response and vaccine parameters. Cancer immunology, immunotherapy. 2009; 58:1-14.

29. Vasilakos JP and Tomai MA. The use of Toll-like receptor $7 / 8$ agonists as vaccine adjuvants. Expert review of vaccines. $2013 ; 12: 809-819$.

30. Skold AE, van Beek JJ, Sittig SP, Bakdash G, Tel J, Schreibelt G and de Vries IJ. Protamine-stabilized RNA as an ex vivo stimulant of primary human dendritic cell subsets. Cancer immunology, immunotherapy. 2015; 64:1461-1473.

31. Krieg AM. CpG motifs in bacterial DNA and their immune effects. Annual review of immunology. 2002; 20:709-760.

32. Vollmer J and Krieg AM. Immunotherapeutic applications of CpG oligodeoxynucleotide TLR9 agonists. Advanced drug delivery reviews. 2009; 61:195-204.

33. Mosca F, Tritto E, Muzzi A, Monaci E, Bagnoli F, Iavarone C, O’Hagan D, Rappuoli R and De Gregorio E. Molecular and cellular signatures of human vaccine adjuvants. Proceedings of the National Academy of Sciences of the United States of America. 2008; 105:10501-10506.

34. Klaschik S, Tross D and Klinman DM. Inductive and suppressive networks regulate TLR9-dependent gene expression in vivo. Journal of leukocyte biology. 2009; 85:788-795.

35. Lindqvist M, Nookaew I, Brinkenberg I, Samuelson E, Thorn $\mathrm{K}$, Nielsen J and Harandi AM. Unraveling molecular signatures of immunostimulatory adjuvants in the female genital tract through systems biology. PloS one. 2011; 6:e20448.
36. Oberg AL, Kennedy RB, Li P, Ovsyannikova IG and Poland GA. Systems biology approaches to new vaccine development. Curr Opin Immunol. 2011; 23:436-443.

37. Germain RN. Vaccines and the Future of Human Immunology. Immunity. 2010; 33:441-450.

38. Li S, Rouphael N, Duraisingham S, Romero-Steiner S, Presnell S, Davis C, Schmidt DS, Johnson SE, Milton A, Rajam G, Kasturi S, Carlone GM, Quinn C, et al. Molecular signatures of antibody responses derived from a systems biology study of five human vaccines. Nature immunology. 2014; 15:195-204.

39. Tel J, Koornstra R, de Haas N, van Deutekom V, Westdorp H, Boudewijns S, van Erp N, Di Blasio S, Gerritsen W, Figdor CG, de Vries IJ and Hato SV. Preclinical exploration of combining plasmacytoid and myeloid dendritic cell vaccination with BRAF inhibition. Journal of translational medicine. 2016; 14:88.

40. Tel J, Smits EL, Anguille S, Joshi RN, Figdor CG and de Vries IJ. Human plasmacytoid dendritic cells are equipped with antigen-presenting and tumoricidal capacities. Blood. 2012; 120:3936-3944.

41. Hug N, Longman D and Caceres JF. Mechanism and regulation of the nonsense-mediated decay pathway. Nucleic acids research. 2016; 44:1483-1495.

42. Cella M, Jarrossay D, Facchetti F, Alebardi O, Nakajima H, Lanzavecchia A and Colonna M. Plasmacytoid monocytes migrate to inflamed lymph nodes and produce large amounts of type I interferon. Nature medicine. 1999; 5:919-923.

43. Caux C, Massacrier C, Vanbervliet B, Dubois B, de SaintVis B, Dezutter-Dambuyant C, Jacquet C, Schmitt D and Banchereau J. CD34+ hematopoietic progenitors from human cord blood differentiate along two independent dendritic cell pathways in response to GM-CSF+TNF alpha. Advances in experimental medicine and biology. 1997; 417:21-25.

44. Fleetwood AJ, Dinh H, Cook AD, Hertzog PJ and Hamilton JA. GM-CSF- and M-CSF-dependent macrophage phenotypes display differential dependence on type I interferon signaling. Journal of leukocyte biology. 2009; 86:411-421.

45. Xu Y, Zhan Y, Lew AM, Naik SH and Kershaw MH. Differential development of murine dendritic cells by GM-CSF versus Flt3 ligand has implications for inflammation and trafficking. Journal of immunology. 2007; 179:7577-7584.

46. van Nieuwenhuijze AE, Coghill E, Gray D, Prato S, Metcalf D, Alexander WS and Wicks IP. Transgenic expression of GM-CSF in T cells causes disseminated histiocytosis. The American journal of pathology. 2014; 184:184-199.

47. Fleetwood AJ, Lawrence T, Hamilton JA and Cook AD. Granulocyte-macrophage colony-stimulating factor (CSF) and macrophage CSF-dependent macrophage phenotypes display differences in cytokine profiles and transcription 
factor activities: implications for CSF blockade in inflammation. Journal of immunology. 2007; 178:5245-5252.

48. Esashi E, Wang YH, Perng O, Qin XF, Liu YJ and Watowich SS. The signal transducer STAT5 inhibits plasmacytoid dendritic cell development by suppressing transcription factor IRF8. Immunity. 2008; 28:509-520.

49. Nicholson P, Yepiskoposyan H, Metze S, Zamudio Orozco $\mathrm{R}$, Kleinschmidt $\mathrm{N}$ and Muhlemann $\mathrm{O}$. Nonsense-mediated mRNA decay in human cells: mechanistic insights, functions beyond quality control and the double-life of NMD factors. Cellular and molecular life sciences. 2010; 67:677-700.

50. Chang YF, Imam JS and Wilkinson MF. The nonsensemediated decay RNA surveillance pathway. Annual review of biochemistry. 2007; 76:51-74.

51. Stock AT, Hansen JA, Sleeman MA, McKenzie BS and Wicks IP. GM-CSF primes cardiac inflammation in a mouse model of Kawasaki disease. The Journal of experimental medicine. 2016

52. Shalek AK, Satija R, Shuga J, Trombetta JJ, Gennert D, Lu D, Chen P, Gertner RS, Gaublomme JT, Yosef N, Schwartz S, Fowler B, Weaver S, et al. Single-cell RNA-seq reveals dynamic paracrine control of cellular variation. Nature. 2014; 510:363-369.

53. Schinnerling K, Garcia-Gonzalez $\mathrm{P}$ and Aguillon JC. Gene Expression Profiling of Human Monocyte-derived
Dendritic Cells - Searching for Molecular Regulators of Tolerogenicity. Frontiers in immunology. 2015; 6:528.

54. Byron SA, Van Keuren-Jensen KR, Engelthaler DM, Carpten JD and Craig DW. Translating RNA sequencing into clinical diagnostics: opportunities and challenges. Nature reviews Genetics. 2016; 17:257-271.

55. Worah K, Mathan TS, Vu Manh TP, Keerthikumar S, Schreibelt G, Tel J, Duiveman-de Boer T, Skold AE, van Spriel AB, de Vries IJ, Huynen MA, Wessels HJ, Gloerich J, et al. Proteomics of Human Dendritic Cell Subsets Reveals Subset-Specific Surface Markers and Differential Inflammasome Function. Cell reports. 2016; 16:2953-2966.

56. Schreibelt G, Klinkenberg LJ, Cruz LJ, Tacken PJ, Tel J, Kreutz M, Adema GJ, Brown GD, Figdor CG and de Vries IJ. The C-type lectin receptor CLEC9A mediates antigen uptake and (cross-)presentation by human blood BDCA3+ myeloid dendritic cells. Blood. 2012; 119:2284-2292.

57. Robinson MD, McCarthy DJ and Smyth GK. edgeR: a Bioconductor package for differential expression analysis of digital gene expression data. Bioinformatics. 2010; 26:139-140.

58. McCarthy DJ, Chen Y and Smyth GK. Differential expression analysis of multifactor RNA-Seq experiments with respect to biological variation. Nucleic acids research. 2012; 40:4288-4297. 